\title{
The State of Diversity, Equity \& Inclusion in Business School Case Studies
}

\author{
Genevieve Smith \\ University of California, Berkeley \\ Kellie McElhaney \\ University of California, Berkeley \\ Diana Chavez-Varela \\ University of California, Berkeley
}

Case studies - using real-life business situations or imagined business scenarios - are a key pedagogical tool for instruction within management education programs that inform students about business processes, decision making, strategy, and leadership and management challenges. However, published case studies used in business schools globally primarily include White male protagonists and do not incorporate key topics related to diversity, equity and inclusion (DEI). This study analyzes trends in the identity/ies of protagonists in case studies, as well as in topics related to DEI. Limitations and implications for case study authors and faculty, business schools and case study publications are also discussed.

Keywords: diversity, equity, inclusion, management education, case studies, business schools

\section{INTRODUCTION}

Case studies - using real life business situations or imagined business scenarios - are a key pedagogical tool for instruction within management education programs. Case studies are effective and important teaching tools that inform students about business processes, decision making, strategy, and leadership and management challenges. The extent to which case studies are used varies among schools, with Harvard leading the way at an estimated $80 \%$ of teaching in its MBA program delivered through case studies as of 2012 (Byrne, 2012). However, published case studies used in business schools globally primarily include White male protagonists (Moules, 2018) and often do not incorporate key topics related to diversity, equity and inclusion (DEI) that are critical for businesses in an increasingly interconnected world and society. Furthermore, while there has been some effort to enhance the number of case studies with diverse protagonists in particular, this does not necessarily translate to an increased use of these types of case studies in classroom settings as professors often use the same case studies over time.

This study presents an analysis of trends in 1) DEI-related case studies and 2) case studies with diverse protagonists. In discussing diversity, we define diversity as incorporating the wide variety of shared and different personal and group characteristics among human beings, including but not limited to race, ethnicity, gender, age, ability, religion, sexual orientation, and socio-economic status. The study was conducted following the creation of a case compendium developed by the Center for Equity, Gender, and 
Leadership (EGAL) at the UC Berkeley Haas School of Business, which includes: case studies with diverse protagonists, and case studies focusing on DEI-related issues and opportunities.

\section{LITERATURE REVIEW}

\section{Lack of Diversity in Published Case Studies}

While the numbers vary slightly and vary depending on the platform that case studies are accessed from, the conclusion remains the same - there is an immense lack of diversity in published case studies. Of the approximately 19,000 cases on Harvard Business Publishing (HBP) Education cases (which comprise $\sim 80 \%$ of cases used in business schools globally by some estimates), previous HBS faculty have estimated that $1 \%$ as of 2017 include a Black executive as a protagonist or central decision-making figure (Ethier, 2017) (From our own findings, approximately $1.3 \%$ of cases on HBP appear in searches for "African American" or "Black"). An analysis of 73 award-winning and best-selling cases from the Case Center (another main distributor of case studies for business schools) between 2009-2015 revealed that women are protagonists in only 11\% (Symons, 2016). It is unclear how many of these case studies include a protagonist that experiences overlapping forms of discrimination based on social categorizations - for example, an under-represented minority (URM) and female - illustrating the likely extreme lack of intersectionality. There is limited information on the percent or number of cases that incorporate concepts of DEI - and when they do, these are often in case studies focused on issues and implications for Human Resources (HR).

\section{Why Do Business Schools Need More Case Studies With Diverse Protagonists \& Case Studies on DEI Topics?}

The lack of diverse protagonists in cases perpetuates and reinforces a status quo in which traditional business leaders are primarily both male and White. This perpetuates the idea that men are at the center of business and unintentionally depicts strong business leadership as masculine. Showing one model of leadership implicitly signals that women are not suited for leadership and deprives students of alternative role models for leadership identities (Symons \& Ibarra, 2014). Further, even when cases have protagonists that are not White men, case studies often perpetuate harmful stereotypes and gender norms such as women depicted as more emotional, less visionary and less agentic than men (Soule, et. al, 2019; Sharen \& McGowan, 2018). Graduate students exposed to case studies with diverse business leaders may benefit from a role model effect in which students relating to those diverse leaders can have better self perceptions and are more confident, as well as perform better (Ammerman, et. Al, 2019).

The lack of case studies on DEI topics has implications for preparing students adequately for their corporate leadership roles. There are various business benefits for organizations and individuals to promote DEI. While this brief will not delve into the business case for diversity, at its core, increasing diversity at organizations is associated with increased financial performance, innovation, and productivity, among other benefits (Center for Equity, Gender, and Leadership, 2020). In addition, more equitable organizations can reduce the incidence of sex-based and other forms of harassment, and thus the associated costs, including reductions in workers' productivity, loss of workers who quit or transfer in the face of harassment and reduced ability to recruit top talent due to reputational damage. Interestingly - and more specific to gender - promoting gender equity and changing the definition of manhood might also help organizations behave more ethically and improve their long-term returns (Kennedy \& Kray, 2014). Beyond promoting DEI in the workplace, companies can also benefit from promoting DEI in their supply chains, as well as in the marketing, sales and distribution of products and services. For example, Unilever's purpose driven brands (which are linked to social purposes related to DEI and/or environmental sustainability) are growing 69\% faster than the rest of the business and delivering $75 \%$ of the company's growth (Unilever, 2019). As an additional example, Google has and continues to expand its positions with a focus on "equity" across business functions. Teams (some new and several expanding) include, for example: Equity engineering, Inclusive products, Machine Learning Fairness, D\&I, and more. The rapid expansion of positions linked to equity include HR / DEI but span beyond. In the Bay area, technology is linked to various implications for equity and inclusion alongside risks and businesses for opportunities. This is further reflected in the 2019 
statement from the Business Roundtable reflecting on the purpose of business to commit to supporting all stakeholders, not just shareholders.

Integrating case studies related to diversity, equity and inclusion can (1) foster cultural sensitivity among students; (2) equip students to manage real-life scenarios in which varying perspectives and lived experiences come into play; (3) prepare students for increasingly diverse workplaces where DEI is a strategic advantage; and (4) learn about critical and timely strategies to promote equity and inclusion throughout the business value chain - from leadership ranks and the workplace through developing, marketing and distributing products and services.

Finally, business schools are increasingly prioritizing advancement of DEI in recruitment, the learning environment and in curriculum. Within the top 10 business schools of the world, although there is an increase in acceptance of candidates representing a wide range of profiles through initiatives such as Minority Recruitment Programs, gaps remain. In the United States, the average proportion of international students in the Financial Times' 2019 top MBA schools was $36.4 \%$, while women account for $34.8 \%$ of MBA classes at US schools on average (Moules, 2019). For US ethnic minorities, at the top 10 business schools, numbers fluctuate between 19.5\% at Dartmouth Tuck and 34.1\% at Penn Wharton (Ethier, 2020). Numbers of Black American students are not shared across all schools, but at Harvard Business School 5\% of students in 2019 were Black, which was the same as in 2008 (Fernandes, 2019). This number is reflected in GMAT examinations, where only 8\% were Black Americans in 2016 (Daniel, et. al, 2018). The knock on effect is the industry pipeline - only $3 \%$ of executive and senior-level positions within private industry are Black Americans, with 4\% for Hispanic Americans (Daniel, et. al, 2018).

Increasingly, the graduate business education industry is recognizing the importance of improving the representation of more diverse perspectives in their curriculum. Top MBA programs - including at UC Berkeley, Harvard, Stanford, and Yale, among others - have affirmed their commitment to supporting diversity, equity, and inclusion through initiatives in their own community, teaching, and research as well as through the recruitment of diverse students, faculty, and staff. At UC Berkeley's Haas Business School, DEI is a clear priority of the school and Haas has a robust strategy to advance DEI. An integral part of this strategy is advancing recruitment of diverse students. As Haas continues to increase diversity among the student body it is critical these students see people similar to themselves represented as leaders in their business school curriculum, including case studies. Furthermore, Haas also seeks to advance "equity fluency" among its students who represent current and future leaders in the business world globally. A term coined by EGAL, Equity Fluent Leaders understand the value of different lived experiences and use their power to address barriers, increase access, and drive change for positive impact.

\section{METHODOLOGY}

The objective of this research was to identify, categorize and analyze case studies with diverse protagonists and case studies that build "equity fluency" by focusing on DEI-related topics. Specifically, we sought to evaluate the trends and gaps among these case studies and present implications for writers of cases, faculty, students, and companies.

\section{Discovery \& Selection Process of Case Studies}

To discover case studies, we began by collating a list of relevant publishers and repositories of business school case studies. We identified leading publishers, including: Amity Business Academies, Babson College Case Studies, Berkeley Haas Case Series, Business Case Journal, California Management Review, Columbia CaseWorks, Copenhagen Business School, Darden Business Publishing, ESSEC Business School, Harvard Business Publishing, IBS Case Development Center, IMD Case Studies, INSEAD, Ivey Publishing, Stanford Business School Case Database, and The Case Centre. Then we used the following search terms in the search engines of each publisher: underrepresented minorities, minorities, URMs, Black, African American, Hispanic, Latino, Latinx, disability, women, gender, immigrant, refugee, asylee, LGBTQ+, lesbian, gay, bisexual, transgender, queer, diversity, inclusion and empowerment. In addition to case studies, the search results included articles and journals, which needed to be screened. The first 10 
Search Engine Results Pages (SERP) for each website were reviewed in order of appearance (e.g., 100-120 cases) per search term. The algorithm of cases prioritized relevance and popularity of the query. Using the search terms on different platforms revealed varied results in terms of the number of case studies with diverse protagonists and cases on DEI-related topics. Many searches resulted in less than 10 pages, in which case all pages were reviewed. The results displayed on the SERP displayed the title of the case study, the case abstract, and the keywords that matched with the content. Due to most portals' algorithms, each case study recommended similar cases with keywords related to the initial search terms.

The main platform where cases were gathered from is Harvard Business Publishing (HBP). HBP is considered the leading provider of teaching materials for management education and comprises $80 \%$ of cases used in business schools globally by some estimates and includes cases from various institutions and partner collections (Ethier, 2017). Given that this publisher houses the vast majority of business school case studies online, we reviewed additional SERPs for this publication.

Given that full case studies are behind paywalls, case studies were reviewed and selected based on their abstract. Cases that did not have an abstract could thus not be reviewed. Cases that included a description but did not include the learning objective were reviewed closely to determine if they were suitable for further analysis. In some cases, the search term "diversity" included phrases such as "diversified investment platform comprising hedge funds," "diversity of the investor base", and "a diverse profile." After close review, cases that did not refer to diversity as "DEI" were not included.

We also searched for lists of relevant compiled case studies from the different platforms and publishers. For example, there was a list of "Cases with Female Protagonists" compiled by the Harvard School Gender Initiative. Some cases included in this list did not include a description of the protagonists' identity in the abstract of the case study, but were still categorized as gender diversity. We did not locate any lists highlighting case studies pertinent to issues of DEI.

\section{Analysis of Case Studies}

To prepare for our analysis of the case studies, we categorized case studies in the following topics: Discipline, Industries and Sectors, Identity/ies of Protagonists (for diverse protagonist cases), Identity/ies of Focus (for DEI-related cases), and Geographic Breadth. See the Appendix for more details on each of these categorizations. Other information tracked on case studies includes Description of the Case Study, Learning Objective, Author(s), Publisher's Name, Publication Date, and Revision date (if applicable).

The list of industries and sectors was based on the U.S. Department of Labor Statistics (2020) which includes ten main industries: Natural Resources and Mining, Construction, Manufacturing, Trade, Transportation, and Utilities, Information, Financial Services, Professional and Business Services, Education, Health Services, and Social Assistance, Leisure and Hospitality, Other Services, and Public Administration.

The list of disciplines were drawn from the University of Nevada's College of Business website, given its comprehension and detail and included: Accounting, Economics, Entrepreneurship, Finance, Information Systems, International Business, Management, and Marketing. Additional disciplines were incorporated into our list based on the way publishers categorized the discipline of their case study, and included: Business and Government Relations, Business Ethics, Business Information Systems, Law, Leadership, Operations Management, Human Resource Management / Organizational Behavior, Political Economy, Strategy, Supply Chain, and Negotiation.

The identification of identities was based on the description of the case study. We included the following identities in our compendium and analysis: Age, Asylee and Refugee Status, Gender, Immigrant/ First-generation, Ability Status, Political Views, Race/Ethnicity, Religion/ Spirituality, Sexual Orientation, and Socio-economic Status. For the cases with diverse protagonists, when not made explicit in the case study description, we tried to confirm whether the individual was diverse in terms of race/ethnicity and gender through online research. However, without self-identification of the referenced individuals, these categories are subject to further inquiry. Not all cases disclosed how each protagonist identifies themselves and we did not make any assumptions based on their name. We recognize that people's diverse identity may be hidden, may be fluid or undefined, and/or cannot be simply categorized into "one bucket". We also 
recognize this exercise is limited as the description is likely not inclusive of the various identities a certain individual identifies with.

For each category, we calculated percentages of occurrence from the overall number of case studies. The percentages are based on the percent the topic is present throughout the 215 cases for DEI-related cases or 215 cases for diverse protagonist cases.

\section{FINDINGS}

\section{Protagonist Identities in Published Case Studies}

Before diving into an analysis of the case studies we collected in our Case Compendium, we provide estimates for protagonists of different identities in published case studies more broadly. Of our search terms, the greatest number of results on Harvard Business School Publishing for "main cases" was for "woman" at 550 results (or $2.8 \%$ of main cases on the platform). Adding results from the words "gender" and "she" brings the total "main case" results to 1826 (or $9.45 \%$ of total cases). Based on this, we can estimate $9.45 \%$ of cases have protagonists identifying as female on HBP. "African American" and "Black" revealed 256 results (or $1.3 \%$ of main cases on the platform). These numbers match with prior estimates outlined in the background section. This does not necessarily correlate to percent of cases with protagonists that identify according to these identities, but illustrates if those identities were mentioned in the case descriptions and serves as an estimate.

\section{Findings in Case Studies With Diverse Protagonists}

We catalogued 215 case studies with diverse protagonists. Diverse protagonists are defined case studies portraying people that are not in the predominant and/or most powerful identity groups of a particular sector. In North America, the word "diversity" is often strongly associated with racial diversity or gender diversity. Those are just two dimensions of human reality and two different identities. Diversity also includes differences in sexual orientation, income, ability, and other various domains.

Within the cases identified and entered in our case compendium (including cases from HBP among other publishers), we find similar rates to those identified in the search results. Of the 215 catalogued case studies, $83.72 \%$ portray a protagonist with Gender diversity and $28.84 \%$ portray a protagonist with diversity of Race / Ethnicity. Most case studies that had identity/ies of focus on Gender diversity had White female protagonists, while most case studies with race / ethnicity diversity were about men. Various case studies highlight more than one identity: 40 case studies (18.60\%) explicitly highlight a protagonist with diversity reflecting both Gender and Race / Ethnicity. Only $4.65 \%$ of the case studies provided examples of Sexual Orientation diversity. Only $0.93 \%$ of the case studies highlighted a character with Political Views, Religious / Spiritual, Abilities, Socio-economic diversity.

TABLE 1

DIVERSE PROTAGONISTS CASE STUDIES: IDENTITY/IES OF PROTAGONISTS

\begin{tabular}{|l|c|c|}
\hline \multicolumn{1}{|c|}{ Identity of Protagonist } & $\begin{array}{c}\text { Number of occurrences in 215 } \\
\text { cases (\#) }\end{array}$ & Percentage of 215 cases (\%) \\
\hline Age & 12 & $5.58 \%$ \\
\hline Asylee and Refugee & 2 & $0.93 \%$ \\
\hline Gender & 180 & $83.72 \%$ \\
\hline Immigrant/First-generation & 0 & $0.00 \%$ \\
\hline Abilities & 2 & $0.93 \%$ \\
\hline Political Views & 2 & $0.93 \%$ \\
\hline Race / Ethnicity & 62 & $28.84 \%$ \\
\hline Religious / Spiritual & 2 & $0.93 \%$ \\
\hline
\end{tabular}




\begin{tabular}{|l|c|c|}
\hline Sexual Orientation & 10 & $4.65 \%$ \\
\hline Socio-economic & 2 & $0.93 \%$ \\
\hline Not specified / General & 0 & $0.00 \%$ \\
\hline
\end{tabular}

\section{Disciplines}

The majority of disciplines that included diverse protagonists were Human Resources / Organizational Behavior (40\%), Entrepreneurship (25.58\%), Marketing (8.37\%), General Management (6.51\%), and Business Ethics (5.12\%). None of the case studies included disciplines of Business Information Systems, Law, and Political Economy.

TABLE 2

DIVERSE PROTAGONIST CASE STUDIES: DISCPLINE

\begin{tabular}{|l|c|c|}
\hline \multicolumn{1}{|c|}{ Discipline } & $\begin{array}{c}\text { Number of occurrences in 215 } \\
\text { cases (\#) }\end{array}$ & Percentage of 215 cases (\%) \\
\hline $\begin{array}{l}\text { Accounting and Finance } \\
\text { Business and Government } \\
\text { Relations }\end{array}$ & 11 & $5.12 \%$ \\
\hline Business Ethics & 11 & $2.79 \%$ \\
\hline Business Information Systems, & 0 & $5.12 \%$ \\
\hline Economics & 5 & $0.00 \%$ \\
\hline Entrepreneurship & 55 & $2.33 \%$ \\
\hline General Management & 14 & $25.58 \%$ \\
\hline Human Resource Management / & 86 & $6.51 \%$ \\
\hline Organizational Behavior & 1 & $40.00 \%$ \\
\hline Information Systems & 1 & $0.47 \%$ \\
\hline International Business & 0 & $0.47 \%$ \\
\hline Law & 3 & $0.00 \%$ \\
\hline Leadership & 18 & $1.40 \%$ \\
\hline Marketing & 7 & $8.37 \%$ \\
\hline Operations Management & 0 & $3.26 \%$ \\
\hline Political Economy & 5 & $0.00 \%$ \\
\hline Strategy & 2 & $2.33 \%$ \\
\hline Supply Chain & 1 & $0.93 \%$ \\
\hline Negotiation & 0 & $0.47 \%$ \\
\hline N/A & & $0.00 \%$ \\
\hline
\end{tabular}

\section{Industries and Sectors}

The most commonly referred industries were Financial Services (21.86\%), Information (16.74\%), Trade, Transportation, and Utilities (14.88\%), Manufacturing (8.84\%), and Education, Health Services, and Social Assistance (8.37\%). Few case studies highlighted the industry sector of Natural Resources and Mining (1.86\%). Only 1 case study $(0.47 \%)$ focused on the industry of Construction. 
TABLE 3

DIVERSE PROTAGONIST CASE STUDIES: INDUSTRIES AND SECTORS

\begin{tabular}{|l|c|c|}
\hline \multicolumn{1}{|c|}{ Industries and Sectors } & $\begin{array}{c}\text { Number of occurrences in 215 } \\
\text { cases (\#) }\end{array}$ & Percentage of 215 cases (\%) \\
\hline Natural Resources and Mining & 4 & $1.86 \%$ \\
\hline Construction & 1 & $0.47 \%$ \\
\hline Manufacturing & 19 & $8.84 \%$ \\
\hline Trade, Transportation, and Utilities & 32 & $14.88 \%$ \\
\hline Information & 36 & $16.74 \%$ \\
\hline Financial Services & 47 & $21.86 \%$ \\
\hline Professional and Business Services & 23 & $10.70 \%$ \\
\hline Education, Health Services, and & 18 & $8.37 \%$ \\
\hline Social Assistance & 8 & $3.72 \%$ \\
\hline Leisure and Hospitality & 0 & $0.00 \%$ \\
\hline Other services (except Public & & \\
\hline Administration) & 12 & $3.72 \%$ \\
\hline Public Administration & & $5.58 \%$ \\
\hline N/A & & \\
\hline
\end{tabular}

\section{Geographic Breadth}

We categorized the case studies based on geography and country of focus. Cases where the scenario was focused on 2 or more countries were categorized as Global (7.91\%). Although most retrieved cases took place in the United States $(66.05 \%)$, cases focused internationally mostly took place in Switzerland $(2.33 \%)$, India $(1.86 \%)$, and Japan (1.86\%). Some case studies $(11.63 \%)$ did not disclose a particular geographical location.

TABLE 4

\section{DIVERSE PROTAGONIST CASE STUDIES: GEOGRAPHIC BREADTH}

\begin{tabular}{|l|c|c|}
\hline \multicolumn{1}{|c|}{ Geographic Breadth } & $\begin{array}{c}\text { Number of occurrences in 215 } \\
\text { cases (\#) }\end{array}$ & Percentage of 215 cases (\%) \\
\hline Australia & 1 & $0.47 \%$ \\
\hline Belgium & 1 & $0.47 \%$ \\
\hline Canada & 2 & $0.93 \%$ \\
\hline Denmark & 1 & $0.47 \%$ \\
\hline Finland & 1 & $0.47 \%$ \\
\hline France & 3 & $1.40 \%$ \\
\hline Germany & 2 & $0.93 \%$ \\
\hline India & 4 & $1.86 \%$ \\
\hline Japan & 4 & $1.86 \%$ \\
\hline New Zealand & 1 & $0.47 \%$ \\
\hline Niger & 1 & $0.47 \%$ \\
\hline Nigeria & 1 & $0.47 \%$ \\
\hline Peru & 1 & $0.47 \%$ \\
\hline South Africa & 1 & $0.47 \%$ \\
\hline
\end{tabular}




\begin{tabular}{|l|c|c|}
\hline South Korea & 1 & $0.47 \%$ \\
\hline Spain & 1 & $0.47 \%$ \\
\hline Switzerland & 5 & $2.33 \%$ \\
\hline United Arab Emirates & 1 & $0.47 \%$ \\
\hline United States & 142 & $66.05 \%$ \\
\hline Global & 17 & $7.91 \%$ \\
\hline N/A & 25 & $11.63 \%$ \\
\hline
\end{tabular}

\section{Findings in Diversity, Equity, and Inclusion (DEI) Related Case Studies}

We catalogued 215 case studies on DEI-related case studies. These include case studies that incorporate scenarios reflecting challenges of diversity, equity, and inclusion in the workplace or diversity-informed decisions of a company. This section outlines trends in case study identity/ies of focus, topics, target segment / population, geographic breadth, industry, and discipline.

\section{Identity/ies of Focus}

We explored the identity/ies that case studies focused on. For example, was the case study focused on issues specifically related to women, to African Americans, or perhaps to individuals with lower socioeconomic status? The most common identity of focus in DEI-related cases is "gender" $(40.93 \%)$ followed by race / ethnicity $(20.00 \%)$, and sexual orientation (15.35\%). In $6.05 \%$ out of 215 case studies the identity of focus includes both gender and race / ethnicity diversity. Only $2.33 \%$ of case studies include discussions related to diversity of abilities, first-generation / immigration status or socio-economic status. None of the cases include veterans as an identity of focus. Many of the case studies (30.23\%) discussed DEI-related challenges and opportunities at a high level without focusing on particular identity/ies.

TABLE 5

\section{DEI-RELATED CASE STUDIES: IDENTITY/IES OF FOCUS}

\begin{tabular}{|l|c|c|}
\hline \multicolumn{1}{|c|}{ Identity/ies of Focus } & $\begin{array}{c}\text { Number of occurrences in 215 } \\
\text { cases (\#) }\end{array}$ & Percentage of 215 cases (\%) \\
\hline Gender & 88 & $40.93 \%$ \\
\hline Race / Ethnicity & 43 & $20.00 \%$ \\
\hline Socio-economic & 5 & $2.33 \%$ \\
\hline Sexual Orientation & 33 & $15.35 \%$ \\
\hline Age & 11 & $5.12 \%$ \\
\hline Abilities & 5 & $2.33 \%$ \\
\hline Religious / Spiritual & 8 & $3.72 \%$ \\
\hline Asylee and Refugee & 3 & $1.40 \%$ \\
\hline Immigrant/First-generation & 5 & $2.33 \%$ \\
\hline Political Views & 2 & $0.93 \%$ \\
\hline Veterans & 0 & $0.00 \%$ \\
\hline Not specified / General & 65 & $30.23 \%$ \\
\hline
\end{tabular}

\section{Target Segment/Population}

This category was created to analyze trends in the target population or segment that the case study focuses on. The most common target segments / populations include entry and mid-level employees in the Workplace (54.88\% of DEI-related cases), Corporate Boards / Leadership (15.35\%), followed by Marketplace (10.23\%), General Population (7.91\%), and Entrepreneurs $(5.12 \%)$. The case studies that focused on entry and mid-level employees in the workplace generally addressed a specific DEI challenge 
or opportunity such as a diversity task force to increase diversity in hiring or develop a mentorship program for diverse employees, for example. Case studies that targeted the marketplace included topics such as diversity-informed product development / services and diversity-informed branding and marketing. Case studies targeting the "general population" were varied but included, for example, women around the world, women in a specific country, disenfranchised groups, among others.

Very few cases mentioned DEI-related challenges and opportunities occurring in the Supply Chain $(1.40 \%)$ and among Investors $(0.93 \%)$. For example, a case delving into investing and DEI is "Fairview Capital" (Rogers \& Collins, 2018). The case focused on "the first U.S. private equity fund of funds that focused on investing in private equity and venture capital funds managed by African-Americans and other minority investment managers. This case study focuses on Fairview's strategic decisions that ultimately led to the growth and expansion of its investment portfolio to over $\$ 3$ billion." For some case studies (5.12\%) it was not clear whether there was a specific target segment but rather appeared to examine the topic of DEI broadly.

TABLE 6

DEI-RELATED CASE STUDIES: TARGET SEGMENT/POPULATION

\begin{tabular}{|l|c|c|}
\hline $\begin{array}{c}\text { Target Segment / Population of } \\
\text { the Case Study }\end{array}$ & $\begin{array}{c}\text { Number of occurrences in 215 } \\
\text { cases (\#) }\end{array}$ & Percentage of 215 cases (\%) \\
\hline Workplace & 118 & $54.88 \%$ \\
\hline Corporate Board/leadership & 33 & $15.35 \%$ \\
\hline Marketplace & 22 & $10.23 \%$ \\
\hline Supply chain & 3 & $1.40 \%$ \\
\hline Investors & 2 & $0.93 \%$ \\
\hline Entrepreneurs & 11 & $5.12 \%$ \\
\hline General Population & 17 & $7.91 \%$ \\
\hline Unions & 2 & $0.93 \%$ \\
\hline Academic Leadership & 4 & $1.86 \%$ \\
\hline Students & 6 & $2.79 \%$ \\
\hline Military Official & 1 & $0.47 \%$ \\
\hline N/A & 11 & $5.12 \%$ \\
\hline
\end{tabular}

Topics

To analyze trends related to topics of DEI-related case studies, we categorized DEI-related topics in the following high-level buckets: Diverse Board / org Leadership Gaps / Solutions, Diverse Employee Representation Gaps / Solutions, Compensation \& Benefits, CSR / Foundations, Culture, Diversity and Entrepreneurship Gaps / Solutions, Diversity-Informed Branding / Marketing, Diversity-Informed Investment \& Partnerships, Diversity-Informed Product Development / Services, Labor Rights / Governmental Policy, Navigating Personal Career, and Violence and Harassment.

The five most common primary topics in DEI-related case studies are culture (in $34.88 \%$ of case DEIrelated case studies), followed by Diverse Employee Representation Gaps / Solutions (21.40\%), Navigating Personal Careers (8.84\%), Compensation and Benefits (7.44\%), Diversity and Entrepreneurship Gaps / Solutions (6.98\%), Diverse Board / Organizational Leadership Gaps / Solutions (6.51\%), and Diversityinformed Branding / Marketing (4.19\%). Of the 215 DEI-related case studies, the least common topics include Labor Rights (0.47\%), CSR / Foundations (2.79\%), and Violence and Harassment (4.65\%). We define organizational culture, following the Society for Human Resource Management (SHRM), as consisting of shared beliefs and values established by leaders and then communicated and reinforced through various methods, ultimately shaping employee perceptions, behaviors and understanding. 
TABLE 7

DEI-RELATED CASE STUDIES: DEI TOPIC

\begin{tabular}{|l|c|c|}
\hline \multicolumn{1}{|c|}{ DEI Topics } & $\begin{array}{c}\text { Number of occurrences in 215 } \\
\text { cases (\#) }\end{array}$ & Percentage of 215 cases (\%) \\
\hline $\begin{array}{l}\text { Diversity and entrepreneurship } \\
\text { gaps / solutions }\end{array}$ & 15 & $6.98 \%$ \\
\hline $\begin{array}{l}\text { Diverse employee representation } \\
\text { gaps / solutions }\end{array}$ & 46 & $21.40 \%$ \\
\hline Culture & 75 & $34.88 \%$ \\
\hline Compensation \& Benefits & 16 & $7.44 \%$ \\
\hline Navigating personal career & 19 & $8.84 \%$ \\
\hline $\begin{array}{l}\text { Diversity-informed branding / } \\
\text { marketing }\end{array}$ & 9 & $4.19 \%$ \\
\hline $\begin{array}{l}\text { Diversity-informed investment \& } \\
\text { partnerships }\end{array}$ & 12 & $5.58 \%$ \\
\hline $\begin{array}{l}\text { Diversity-informed product } \\
\text { development / services }\end{array}$ & 10 & $4.65 \%$ \\
\hline CSR / Foundations* & 6 & $2.79 \%$ \\
\hline $\begin{array}{l}\text { Labor rights (Governmental } \\
\text { policy) }\end{array}$ & 1 & $0.47 \%$ \\
\hline $\begin{array}{l}\text { Diverse board / org leadership } \\
\text { gaps / solutions }\end{array}$ & 14 & $6.51 \%$ \\
\hline Violence and Harassment & 10 & $4.65 \%$ \\
\hline N/A & 16 & $7.44 \%$ \\
\hline
\end{tabular}

For each case study, we also categorized and analyzed DEI sub topics. The sub-topics included: Allyship, Changing Norms, Childcare/Eldercare, Discrimination \& Unconscious bias, Dual Career Couple, Economic Empowerment, Hiring \& Recruiting Practices, Mentorship \& Sponsorship, Parental Leave, Pay Equity, Professional Development Programs for Diverse Employees/ERGs, Promotion \& Evaluation Practices, Quotas and Incentives, Retention of Older/ Younger Employees, Return to Work, Sexual or Verbal Harassment, Strategy, Work-life Balance \& Flexible Work, Other, and N/A.

The most common sub-topics include Strategy (14.88\% of DEI-related cases), Hiring and Recruiting (16.28\%), Discrimination and Unconscious Bias (15.35\%). Many of the case studies were categorized as "N/A" (31.63\%). Given our analysis was based on the abstracts of case studies (as outlined in the methodology section), it was not always clear or obvious what the sub-topic(s) were or if the case study had subtopics beyond the primary topic, hence being categorized as N/A. The least common sub-topics included Changing Norms (3.72\%), Allyship (3.26\%), Quotas (2.33\%), Parental Leave (2.79\%), Pay Equity (1.86\%), Retention of Older / Younger Employees (1.86\%), Childcare / Eldercare (1.40\%), and Dual Career Couple $(0.47 \%)$. All of these topics are prevalent in popular discourse, corporate reports and media which further highlights a gap between trends in industry / society and business school case studies. 
TABLE 8

DEI-RELATED CASE STUDIES: DEI SUBTOPIC

\begin{tabular}{|l|c|c|}
\hline \multicolumn{1}{|c|}{ DEI Subtopic } & $\begin{array}{c}\text { Number of occurrences in 215 } \\
\text { cases (\#) }\end{array}$ & Percentage of 215 cases (\%) \\
\hline Allyship & 7 & $3.26 \%$ \\
\hline Changing Norms & 8 & $3.72 \%$ \\
\hline Childcare / eldercare & 3 & $1.40 \%$ \\
\hline Discrimination \& unconscious bias & 33 & $15.35 \%$ \\
\hline Dual Career Couple & 1 & $0.47 \%$ \\
\hline Economic empowerment & 8 & $3.72 \%$ \\
\hline Hiring \& recruiting practices & 35 & $16.28 \%$ \\
\hline Mentorship \& sponsorship & 3 & $1.40 \%$ \\
\hline Parental leave & 6 & $2.79 \%$ \\
\hline Pay equity & 4 & $1.86 \%$ \\
\hline Professional development \\
programs for diverse employees /
\end{tabular}

\section{Disciplines}

The majority of the cases focused on DEI-related issues are in the disciplines of Human Resource Management / Organizational Behavior (58.60\%) and General Management (11.16\%). Entrepreneurship $(8.84 \%)$ and Marketing $(6.05 \%)$ were also some of the most common disciplines in the case studies. Among the least common disciplines, $0.93 \%$ of the case studies had the discipline of Supply Chain. Furthermore, $0.47 \%$ had the discipline of Economics as well as International Business. 
TABLE 9

DEI-RELATED CASE STUDIES: DISCIPLINES

\begin{tabular}{|l|c|c|}
\hline \multicolumn{1}{|c|}{ Discipline } & $\begin{array}{c}\text { Number of occurrences in 215 } \\
\text { cases (\#) }\end{array}$ & Percentage of 215 cases (\%) \\
\hline $\begin{array}{l}\text { Human Resource Management / } \\
\text { Organizational Behavior }\end{array}$ & 126 & $58.60 \%$ \\
\hline General Management & 24 & $11.16 \%$ \\
\hline Entrepreneurship & 19 & $8.84 \%$ \\
\hline Marketing & 13 & $6.05 \%$ \\
\hline Strategy & 11 & $5.12 \%$ \\
\hline Accounting and Finance & 6 & $2.79 \%$ \\
\hline Business and Government & 7 & $3.26 \%$ \\
\hline Relations & 17 & $7.91 \%$ \\
\hline Business Ethics & 0 & $0.00 \%$ \\
\hline Business Information Systems, & 1 & $0.47 \%$ \\
\hline Economics & 0 & $0.00 \%$ \\
\hline Information Systems & 1 & $0.47 \%$ \\
\hline International Business & 0 & $0.00 \%$ \\
\hline Law & 4 & $1.86 \%$ \\
\hline Leadership & 0 & $0.00 \%$ \\
\hline Operations Management & 0 & $0.00 \%$ \\
\hline Political Economy & 2 & $0.93 \%$ \\
\hline Supply Chain & & \\
\hline
\end{tabular}

\section{Geographic Breadth}

We categorized the case studies based on geography and country of focus. Cases where the scenario was focused on 2 or more countries were categorized as Global (13.02\%). Although most retrieved cases took place in the United States $(46.51 \%)$, cases focused internationally mostly took place in Asia. Out of 215 DEI-related case studies, 5.58\% of cases mentioned a company based in India and/or with locations in India. Some case studies (18.60\%) did not disclose a particular geographical location.

\section{TABLE 10 \\ DEI-RELATED CASE STUDIES: GEOGRAPHIC BREADTH}

\begin{tabular}{|l|c|c|}
\hline \multicolumn{1}{|c|}{ Geographic Breadth } & $\begin{array}{c}\text { Number of occurrences in 230 } \\
\text { cases (\#) }\end{array}$ & Percentage of 230 cases (\%) \\
\hline Australia & 1 & $0.47 \%$ \\
\hline Bangladesh & 1 & $0.47 \%$ \\
\hline Belgium & 1 & $0.47 \%$ \\
\hline Canada & 6 & $2.79 \%$ \\
\hline China & 1 & $0.47 \%$ \\
\hline Denmark & 1 & $0.47 \%$ \\
\hline India & 12 & $5.58 \%$ \\
\hline Italy & 1 & $0.47 \%$ \\
\hline Japan & 4 & $1.86 \%$ \\
\hline
\end{tabular}




\begin{tabular}{|l|c|c|}
\hline Lebanon & 1 & $0.47 \%$ \\
\hline Netherlands & 2 & $0.93 \%$ \\
\hline Niger & 1 & $0.47 \%$ \\
\hline Nigeria & 1 & $0.47 \%$ \\
\hline Singapore & 2 & $0.93 \%$ \\
\hline South Korea & 1 & $0.47 \%$ \\
\hline Spain & 2 & $0.93 \%$ \\
\hline Switzerland & 4 & $1.86 \%$ \\
\hline United Arab Emirates & 2 & $0.93 \%$ \\
\hline United Kingdom & 4 & $1.86 \%$ \\
\hline United States & 100 & $46.51 \%$ \\
\hline Global & 28 & $13.02 \%$ \\
\hline N/A & 40 & $18.60 \%$ \\
\hline
\end{tabular}

\section{Industries and Sectors}

The most common industries are Financial Services (21.40\%), Information (14.88\%), and Professional / Business Services (12.09\%). The least common industries are Leisure and Hospitality (2.33\%), Natural Resources and Mining (1.40\%), and Education, Health Services, and Social Assistance (all at 4.19\%). Within education in particular, the main DEI topic(s) of focus were Employee Representation and Culture. Of these case studies $14.42 \%$ did not take place in a particular industry, but were general.

TABLE 11

DEI-RELATED CASE STUDIES: INDUSTRIES AND SECTORS

\begin{tabular}{|l|c|c|}
\hline \multicolumn{1}{|c|}{ Industries and Sectors } & $\begin{array}{c}\text { Number of occurrences in 215 } \\
\text { cases (\#) }\end{array}$ & Percentage of 215 cases (\%) \\
\hline Natural Resources and Mining & 3 & $1.40 \%$ \\
\hline Construction & 0 & $0.00 \%$ \\
\hline Manufacturing & 16 & $7.44 \%$ \\
\hline $\begin{array}{l}\text { Trade, Transportation, and } \\
\text { Utilities }\end{array}$ & 30 & $13.95 \%$ \\
\hline Information & 32 & $14.88 \%$ \\
\hline Financial Services & 46 & $21.40 \%$ \\
\hline Professional and Business Services & 26 & $12.09 \%$ \\
\hline $\begin{array}{l}\text { Education, Health Services, and } \\
\text { Social Assistance }\end{array}$ & 9 & $4.19 \%$ \\
\hline Leisure and Hospitality & 5 & $2.33 \%$ \\
\hline $\begin{array}{l}\text { Other services (except Public } \\
\text { Administration) }\end{array}$ & 1 & $0.47 \%$ \\
\hline Public Administration & 13 & $6.05 \%$ \\
\hline N/A & 31 & $14.42 \%$ \\
\hline
\end{tabular}

\section{LIMITATIONS}

During the discovery, selection, and categorization process of the research, we encountered various limitations. First, our list of DEI-related case studies and case studies with diverse protagonists is not 
exhaustive. While we reviewed up to 10 search pages per query (which are ranked by relevance and popularity) and conducted a more extensive search on HBP, we recognize other cases exist and were not categorized or analyzed. However, based on the algorithms of the platforms, we feel confident that we were able to collect the most popular, relevant and utilized cases.

The classifications and organization of published case studies vary based on the publisher. Most of our case studies were retrieved from Harvard Business Publishing. In their website, case studies are classified by Disciplines, Objectives, Subjects, Geography, and Industry. Other websites did not classify their case studies in the same format and case studies in The Case Centre website did not include any specific information about the Disciplines, Objectives, Subjects, Geography, and Industry of each case study. To ensure consistency between cases on different websites, each case abstract was manually reviewed regardless of which website it was retrieved from. To ensure all cases were categorized accurately, the description of each case study was closely examined to identify the appropriate Disciplines, Objectives, Subjects, Geography, and Industry of each case study. The description of the case studies was also helpful in identifying additional information to include in cases where the Disciplines, Objectives, Subjects, Geography, and Industry were already disclosed. There may be some discrepancies and subjectivity therefore in the categorization of these topics.

One of the greatest challenges of our research was the creation of categories to include in our section for Identity/ies of protagonists and Identity/ies of focus. Only individuals were identified in categories of racial/ethnic diversity or gender diversity, unless another identity was explicitly included in the description of the case. In which case we included these other diverse representations of identity (e.g., sexual orientation, ability status). We recognize this is limited as the description is likely not inclusive of the various identities a certain individual identifies with.

When not made explicit in the case study description, we tried to confirm diversity in categories of race/ethnicity and gender binary through online research, but without self-identification of the referenced individuals, these categories are obviously subject to further inquiry. Not all cases disclosed how each Identity/ies of focus identify themselves and we did not make any assumptions based on their name. We recognize that people's diverse identity may be hidden, may be fluid or undefined, and/or cannot be simply categorized into "one bucket".

We did not make specific identifications - such as Hispanic, Persian, Caucasian - and instead created broader denominations such as Race/ethnicity diversity, given that cases would rarely mention specific details about a person's country of origin or nationality. Since our objective was to make a total count of the amount of cases that would focus, disclose, or incorporate race, gender, and ethnicity, we aimed to make each category as inclusive and comprehensive as possible. This would also help avoid bias errors in the selection criteria and ensure more accuracy, as we would not be able to accurately affirm whether someone identifies as Hispanic, Latino or Mexican American, for example.

Although we aimed to avoid assumptions, our own personal bias could have affected how certain case studies were reviewed. Our educational background and lived experiences impact how we view and categorize some cases, particularly related to DEI topics. We tried to be as objective as possible through known categorizations and definitions, however categorizing in itself can be subjective itself. Diversity can be context specific and, in some cases, difficult to assess (e.g., age diversity) and requires larger contextual knowledge. We tackled this through creating metrics and clear definitions in our methodology and analysis.

Although some case studies were translated from its primary language, all of the cases were read in English. This might also thus limit the amount of case studies drawn from other geographies not primarily English speaking.

\section{DISCUSSION}

\section{DEI Topics and Target Segments}

Among the DEI-related cases, the majority of the disciplines are HR and Organizational Behavior related $(58.60 \%)$. The most common topics are Culture $(34.88 \%)$ followed by Diverse Employee 
Representation Gaps / Solutions (21.40\%). The most common sub-topics include Strategy (14.88\%), Hiring and Recruiting (16.28\%), Discrimination and Unconscious Bias (15.35\%).

DEI-related case studies lack the myriad of topics and scenarios where DEI challenges and opportunities prevail in today's society. Other critical topics are largely missing with $4.65 \%$ mentioning scenarios of Violence and Harassment, $0.47 \%$ including Dual Career Couples, $1.40 \%$ addressing Childcare / Eldercare, 1.40\% addressing Return to Work and 1.86\% discussing Pay Equity. This topical lack among case studies is interesting because these topics are prevalent in popular discourse, corporate reports and media which further highlights a gap (or delay, potentially) between trends in industry / society and business school case studies.

Relatedly, there is a focus of DEI-related cases in the Workplace (54.88\%), but a lack in other key areas. Few cases focus on DEI in the Supply chain $(1.40 \%)$ or among Investors $(0.93 \%)$. Additionally, only $1.86 \%$ of the 215 cases mention scenarios occurring among Academic Leadership. Addressing DEI in academic leadership (i.e. faculty) is of increasing importance to universities. Currently, the lack of diversity among faculty reinforces lack of DEI-related and diverse protagonists cases discussed and incorporated in courses. Hesitancy to incorporate cases with diverse protagonists or on DEI-related topics due to uncertainty around how to discuss and adequately address sensitive diversity topics is common.

\section{Identity/ies of Focus}

There is a lack of cases with protagonists that are not White men. Of the approximately 19,000 cases on HBP, which houses the vast majority of cases used globally, it is difficult to make estimates on cases with diverse protagonists but we do find some indications. Approximately $1.3 \%$ of cases on HBP appear in searches for "African American" or "Black". When searching terms on Harvard Business School Publishing we found 1,826 cases (or $9.45 \%$ of total cases) appearing for "woman", "gender" and "she".

The majority of cases catalogued with diverse protagonists focus on White women. The most common diverse protagonist cases are on White women followed by men of color. Out of 215 cases, $83.72 \%$ portray a protagonist representing gender diversity (i.e. female protagonist) and $28.84 \%$ highlight a protagonist representing race / ethnicity diversity (i.e., under-represented minority (URM)). Several cases have a protagonist that is both female and a URM (18.60\%). Among cases with diverse protagonists, only $4.65 \%$ of cases included a protagonist that identifies as being LGBTQ.

The most common identity of focus in DEI-related cases is gender ( $40.93 \%$ of 215 cases) followed by race / ethnicity (20\%). Few cases (6.05\%) focus on DEI-related issues and opportunities for both race and gender. Many DEI-related cases do not specify a particular identity/ies of focus (30.23\%). Identities beyond gender (particularly cis female) and/or race are lacking, with some identities few and far between. In the DEI-related case studies, only $2.33 \%$ of case studies include discussions focused on diversity of abilities and immigrant / first-generation, and socio-economic diversity. Only $1.40 \%$ of the cases focus on identity/ies related to asylee and refugee diversity. No cases include veterans as an identity of focus.

Among cases focused on Socio-economic status, the majority discuss poverty alleviation programs, underserved communities, loans for low-income women entrepreneurs, and candidates from various "social and cultural backgrounds." Among cases addressing diversity in terms of Sexual Orientation, most mention the topic broadly. Although some cases mention Age diversity broadly, five cases depict scenarios centered on the recruitment/retention of younger and older employees, the role played by older/younger executives, generational diversity, and where young couples face a career decision.

\section{Disciplines}

The most common discipline among the DEI-related case studies is Human Resource Management / Organizational Behavior (58.60\%), followed by General Management (11.16\%). Among the cases with diverse protagonists, Human Resources / Organizational Behavior is also the most common discipline by far $(40.00 \%$ of 215 cases $)$. The second most common discipline in the cases with diverse protagonists is Entrepreneurship (25.58\% of cases). Only $8.84 \%$ of DEI-related cases are on topics of Entrepreneurship. Among diverse protagonists, $9.47 \%$ are on Marketing, for DEI-related cases $6.05 \%$ are on Marketing. 
Various disciplines are almost non-existent among both case study groups. Both lack cases on Leadership (only $1.40 \%$ in diverse protagonists cases and $1.86 \%$ in DEI-related cases). There are also a lack of cases in both case study groups among disciplines of Accounting and Finance, Supply Chain, Political Economy, Economics, International Business and Negotiation. Of the cases with diverse protagonists, the majority of the protagonists with gender diversity are portrayed in the discipline of Entrepreneurship and Human Resource Management / Organizational Behavior.

\section{Industries and Sectors}

The top industry among both case study groups is Financial Services $(21.40 \%$ of DEI-related cases, $21.86 \%$ of diverse protagonists). The second most common industry among both groups is Information (14.88\% of DEI-related cases, $16.74 \%$ of Diverse Protagonist Cases). Among the Diverse Protagonist Cases, the industry of Trade, Transportation and Utilities is also common (14.88\% of cases).

\section{Geography}

Of the 215 DEI-related Case Studies, $46.51 \%$ take place in the United States while only $13.48 \%$ have a global focus. Similarly, $66.05 \%$ of 215 cases with diverse protagonists take place in the United States. Outside of the United States, the majority of DEI-related Case Studies focused internationally mostly take place in India (5.58\%). Outside of the US, the next most common cases with diverse protagonists took place in Switzerland (2.33\%), Japan, and India (both at $1.86 \%$ ).

\section{Perpetuation of Stereotypes}

In addition to the lack of diversity profiles and DEI-related topics, it is important to explore the content of cases, including language used to describe protagonists and scenarios. Indeed, many case studies inadvertently reinforce harmful stereotypes and gender norms. A study examining case studies taught in Stanford's MBA Core Curriculum, found that $16 \%$ of the protagonists were female; but more, these cases were also primarily in "pink" industries (Soule, et. al, 2019). Soule et. al also found that cases with female protagonists reinforced stereotypes of women as communal and men as agentic. The authors found other stereotypes reinforced in cases related to race, national origin and age as well. Similar findings were identified in study by Sharen \& McGowan (2018), which found that $20 \%$ of business school case studies among their sample had female protagonists and those females were represented as emotional, cautious, overwhelmed and less visionary, action-oriented, and innovative than men. In addition, female protagonists' credentials were mentioned more frequently as opposed to their male colleagues. Moreover, a quarter of the reviewed case studies involved a scenario where a female protagonist questions her competence. However, male protagonists did not have the same scenarios.

While we did not analyze text of the case studies as part of this scope, we saw how harmful norms and stereotypes are perpetuated in cases. Indeed, in some retrieved cases, characters' descriptions of gender, race, and ethnicity are presented in problematic ways. For instance, the case study titled "Carmichael Roberts: To Create a Private Equity Firm?" (Rogers \& Cooper, 2017), the authors describes the protagonist as a "rare African-American venture capitalist" instead of "an African-American venture capitalist." The author's selection of the word "rare" may be in reference to fewer venture capitalists that identify as African-American, yet defining an African American as "rare" can unintentionally commodify the protagonist.

In another instance, the case study titled "Organizational Behavior: Management Diversity in the Large Corporation" (Carter, 1993) has language that stereotypes women, Black people, Asians, and Hispanics in the description by mentioning "How do you manage talented people that are different from the typical corporate profile like women, blacks, Asians, Hispanics and others?" This case presents diverse individuals as 'atypical' and as 'others' requiring different management approaches. The case also mentioned, "ways that women and minorities can take responsibility for their own success in the corporate environment." Lastly, the case study, "Director's Dilemma: Balancing Between Quality and Diversity" (Deb \& Sharma, 2017) perpetuates the common narrative of diversity as an exception in admissions acceptances, working against "quality". The case study mentions "One of [the major concerns in the mind of the director of 
admissions] was what was the exact situation of IIM Kashipur in terms of quality and diversity?" The title of the case study as well as the description implies that more diversity in a program equals less quality; this is problematic and does not reflect the wealth of research on the business case for diversity illustrates the business benefits.

Ultimately, it is important to acknowledge that quantity is not enough - cases and authors must also be aware and critical of how they can be perpetuating harmful stereotypes and norms.

\section{Identity/ies of Case Study Authors}

The majority of the primary authors (those first listed) are male in both DEI-related Cases and Diverse Protagonist Case Studies. We did not analyze or explore race / ethnicity. Of the DEI-related cases, 55.35\% of the primary authors are male while $42.33 \%$ are female authors. This doesn't mean that women are not included as additional authors. On the contrary, most cases have multiple authors and include gender diversity among them. However, the primary authors are predominantly male. Since case study publications generally require a professor / faculty member as a first author, this difference could be linked to the representation gaps between male and female faculty in higher education. The gender gap between male and female primary authors is greatest among the Diverse Protagonist Case Studies, with $67.91 \%$ of the primary authors being male while only $32.09 \%$ of the cases have a female primary author.

\section{IMPLICATIONS}

This research has revealed various gaps and opportunities in case studies used in business school curriculum. The workplace and business world is increasingly diverse and dynamic. Based on this analysis, there are implications for case study authors and faculty, business schools and case study publications. We outline the implications and recommendations below.

\section{For Case Study Authors and Faculty}

Case study authors and faculty can consider cases with diverse protagonists and on DEI topics, using resources such as EGAL's Case Compendium to identify cases. Further, case study authors should write and publish more case studies with diverse protagonists -- particularly intersectional identities. The majority of cases with diverse protagonists are on White women followed by men of color. Few case studies incorporate discussion of other identities, especially identities that can be "hidden" such as people of diverse sexual orientation. Case studies that incorporate various intersections of identities are critical.

Case study authors can write and publish on topics of DEI outside of Human Resource Management / Organizational Behavior - and particularly across core curriculum courses. Businesses are integrating DEI considerations across their operations, not just related to HR and the workplace. As examples, Unilever has mandated that none of its marketing perpetuates harmful norms, and that brands must actually promote positive norms. In recent years Google teams focused on equity and inclusion have proliferated across product development and marketing (e.g., Equity Engineering, Machine Learning Fairness, Responsible AI). To reflect these new realities, business schools need to keep up and have cases that incorporate learnings that are necessary for business leaders of today and tomorrow.

Related to language, it is necessary that language written in cases does not commodify / discriminate against certain identities, and/or perpetuate stereotypes and harmful norms. Several case studies incorporated problematic language related to DEI. EGAL has developed a Glossary of Key Terms for Equity Fluent Leaders as a starting point for authors - including DEI language, potentially problematic terms and alternatives, as well as gender pronouns and rules of thumb. However, the reflection of stereotypes and harmful norms in cases highlights a much larger issue of biases of case study authors, which are often faculty.

\section{For Business Schools}

Business schools must encourage and incentivize faculty to utilize case studies with diverse protagonists or case studies on DEI topics in their courses - assuming the case(s) align with their course 
and teaching goals. Many faculty use the same case studies year after year. While this can provide comfort and expertise in facilitating a certain case, there is opportunity to explore diversifying case studies used in classrooms to enhance inclusion and belonging among students.

Business schools can educate case study authors / faculty on topics of power, privilege, discrimination, bias and structural inequities and how they can manifest in the classroom. The trends in case studies around perpetuation of stereotypes and harmful norms reflects biases among case study authors who are faculty members. This is also reflected in the lack of diverse faculty at business schools. While increasing diversity among faculty is important, also critical is working with current faculty around these topics to ensure they are not inadvertently reinforced in education.

Relatedly, business schools must support faculty and lecturers with specific resources and educational opportunities to integrate DEI in the classroom. A constraint to faculty using cases with diverse protagonists or on DEI-related topics is lack of comfort on sensitive topics of diversity. Resources and educational opportunities to learn how to facilitate cases and incorporate DEI topics in their classrooms is important. For example, how can faculty facilitate tough conversations around identity or navigate when different challenges are brought up from students? We encourage business schools to provide educational support, tools and resources for faculty on topics such as navigating tough conversations in the classroom and supporting inclusive classroom environments for students of all identities.

\section{For Case Study Publications}

Case study publications have an important role to play. They can review case study applications and descriptions for problematic language that reinforces stereotypes and harmful norms, and flag this type of language. Further, publishers should incentivize and encourage new case studies. In particular, this includes case studies written on DEI-related topics outside of the workplace and HR and case studies on diverse protagonists. For female protagonists, encourage case studies outside of gendered industries and domains. Lastly, publishers can encourage diversity in terms of who is writing case studies. The majority of case studies - including with diverse protagonists and on DEI topics - are written by men. We have not assumed their race or other aspects of their identity that can be hidden. We encourage case study publications to explore how to incentivize more diversity in case study authors and perspectives.

\section{CONCLUSION}

It is critical that the education system is able to respond to the needs of its students and the evolving business needs, as well as the world more broadly. There is both a gap and an opportunity related to business school case studies. Advancing equity fluency among current and future business leaders is critical for sustainable, successful businesses in an increasingly interconnected world.

\section{ACKNOWLEDGMENTS}

This paper benefitted from the helpful review of Professor Laura Kray at the University of California, Berkeley. We would also like to acknowledge the broader team at the Center for Equity, Gender, and Leadership at Berkeley Haas for their support.

\section{REFERENCES}

Ammerman, C., Trumbore, A., \& Ajayi-Ore, L. (2019, June 24). The case for female protagonists. Harvard Business Publishing Education. Retrieved from https://hbsp.harvard.edu/inspiringminds/the-case-for-female-protagonists

Byrne, J. (2012, November 18). How the world's top business schools teach their students. Poets \& Quants. Retrieved from https://poetsandquants.com/2012/11/18/how-the-worlds-top-businessschools-teach-their-mbas/ 
Carter, T. (1993). Organizational behavior: Management diversity in the large corporation. The Case Centre. Retrieved from https://www.thecasecentre.org/main/products/view?id=23349

Center for Equity, Gender, and Leadership. (2020). Business case for diversity. UC Berkeley Haas School of Business. Retrieved from https://haas.berkeley.edu/equity/industry/efl-knowledgebank/business-case-for-diversity/

Daniel, R., Caruthers, D., Bruggeman, P., Hazenbush, M., Schoenfeld, G., \& Chisholm, A. (2018). Understanding underrepresented populations in the business school pipeline. Graduate Management Admission Council. Retrieved from https://www.gmac.com//media/files/gmac/research/research-report-series/rr-16-02-underrepresented-populations-v2.pdf

Deb, M., \& Sharma, V.K. (2017). Director's dilemma: Balancing between quality and diversity. The Case Centre. Retrieved from https://www.thecasecentre.org/main/products/view?id=142126

Ethier, M. (2017, April 27). HBS case studies need diversity - Now. Poets \& Quants. Retrieved from https://poetsandquants.com/2017/04/27/hbs-prof-case-studies-need-diversity-now/?pqcategory=business-school-news

Ethier, M. (2020, April 6). Minorities at the top 25 U.S. MBA programs. Poets \& Quants. Retrieved from https://poetsandquants.com/2020/04/06/minorities-at-the-top-25-u-s-mba-programs/

Fernandes, D. (2019, June 1). At Harvard Business School, diversity remains elusive. The Boston Globe. Retrieved from https://www.bostonglobe.com/metro/2019/06/01/harvard-business-schooldiversity-remains-elusive/bpyxP4cE1iCQJdLbHQEaQI/story.html

Kennedy, J., \& Kray, L. (2014). Who is willing to sacrifice ethical values for money and social status? Gender differences in reactions to ethical compromises. Social Psychological and Personality Science, 5(1), 52-59.

Moules, J. (2018, September 23). MBA case studies lack female leaders. Financial Times. Retrieved from https://www.ft.com/content/036144a8-9f07-11e8-85da-eeb7a9ce36e4

Moules, J. (2019, June 14). Why business schools still have a diversity problem. Financial Times. Retrieved from https://www.ft.com/content/2276cfle-86bc-11e9-97ea-05ac2431f453

Rogers, S.S., \& Collins, D. (2018, October 25). Fairview Capital. Harvard Business Publishing. Retrieved from https://hbsp.harvard.edu/product/319050-PDFENG?Ntt=Steven+rogers\&itemFindingMethod $=$ Search

Rogers, S., \& Cooper, K. (2017). Carmichael Roberts: To create a private equity firm? Harvard Business School. Retrieved from https://www.hbs.edu/faculty/Pages/item.aspx?num=52088

Sharen, C.M., \& McGowan, R.A. (2018). Invisible or clichéd: How are women represented in business cases? Journal of Management Education, 43(2), 129-173.

Soule, S. A., Drabkin, D., \& Mackenzie, L. (2019, June 24). The stereotypes in MBA case studies. Harvard Business Review. Retrieved from https://hbr.org/2019/06/the-stereotypes-in-mba-casestudies

Symons, L. (2016, March 10). Only 11\% of top business school case studies have a female protagonist. Harvard Business Review. Retrieved from https://hbr.org/2016/03/only-11-of-top-businessschool-case-studies-have-a-female-protagonist

Symons, L., \& Ibarra, H. (2014, April 28). What the scarcity of women in business case studies really looks like. Harvard Business Review. Retrieved from https://hbr.org/2014/04/what-the-scarcityof-women-in-business-case-studies-really-looks-like

Unilever. (2019). Unilever's Purpose-led Brands Outperform. Retrieved from https://www.unilever.com/news/press-releases/2019/unilevers-purpose-led-brandsoutperform.html 


\section{APPENDIX}

The categorizations used in the analysis are outlined below.

\section{Description of Case Study}

The majority of case studies included a description, which was utilized to analyze and categorize its Target Segment, Identity/ites of Focus, Main Diversity and Inclusion Topic, and Geographic Location.

\section{Learning Objective}

The majority case studies included the learning objective of the case study, which was also utilized to analyze and categorize its Target Segment, Identity/ites of Focus, Main Diversity and Inclusion Topic, and Geographic location. When case studies did not include a learning objective, the description of the case study was mostly utilized to determine such information.

\section{Discipline}

Accounting and Finance, Business and Government Relations, Business Ethics, Business Information Systems, Economics, Entrepreneurship, Finance, General Management, Information Systems, International Business, Marketing, Operations Management, Human Resource Management / Organizational Behavior, and Strategy.

\section{Potential Core Courses Appropriate to Use}

Applied Innovation Elective, Brand Management, Business History, Career Planning/Advancement, Corporate Social Responsibility, Corporate Strategy, Data and Decisions, Economics for Business Decision-Making, Ethics and Responsibility in Business, Financial Accounting, Fundamentals of Design Thinking, General Management, Growth Strategy, International Business, Introduction to Finance, Leadership Communication, Leading People, Macroeconomics in the Global Economy, Marketing Strategy, Negotiations, Operations, Organizational Culture, Organizational Development, Portfolio Management, Social Entrepreneurship, and Strategic Leadership. This category emerged from understanding if disciplines could be linked to courses provided by the Haas School of Business. Potential Core Courses were selected based on UC Berkeley's MBA Curriculum. To ensure each case study was categorized appropriately, courses were selected based on the description of the case, the key words listed in the "Subjects" section disclosed within the Case Study, and by cross-referencing the syllabus of each course with the description of the case study. (Verify if there is a leadership course that was added from another university's curriculum).

\section{Identity/ies of Protagonists}

Age Diversity, Asylee/Refugee Diversity, Gender Diversity, Immigrant/First-generation Diversity, Physical and Psychological Diversity, Political Views Diversity, Racial/Ethnic Diversity, Religious/Spiritual Diversity, Sexual Orientation Diversity, Socio-economic Diversity, N/A. To avoid excluding certain diversity identities, categories such as "Age Diversity", "Gender Diversity", "Religious Diversity" were created. Although it is not an exhaustive list of all possible identities a person can relate to, this section was done with the aim of understanding trends and gaps in the way profiles are portrayed in case studies. To ensure the research was the least biased as possible, each case study was categorized based on the description provided. Given that it is not possible to accurately define a protagonists' gender, religion, and age based on a search engine search, the categories of "Religious Diversity", "Political Diversity", "Refugee/Asylee Diversity" etc were not selected unless the description disclosed this information. If we were unable to confirm such information, we did not include the category.

\section{Industry}

Our list for Industry Sector was retrieved from the United States Department of Labor which grouped industries in the United States into ten main categories including: Natural Resources and Mining, 
Construction, Manufacturing, Trade, Transportation, and Utilities, Information, Financial Services, Professional and Business Services, Education and Health Services, Leisure and Hospitality, and Other Services.

\section{Publishers' Name}

ABI/Inform Global, Asian Case Research Journal, Asian Case Research Journal, Babson College Case Studies, Berkeley Haas School of Business, Business Case Journal, Business Source Complete, California Management Review, Darden Business Publishing, Emerald Insight Case Studies, Harvard Business Publishing, IMD Case Studies, Ivey Cases (University of Western Ontario Free Cases), Journal of Business Case Studies, Journal of Business Cases and Applications, Journal of Case Research in Business and Economics, Journal of Information Technology Teaching Cases, LearningEdge at MIT Sloan, MarketLine Advantage, Stanford Business School Case Database, The Asian Business Case Centre, and The Case Center. 